\title{
Measurement of Emotion Dysregulation in Adolescents
}

\author{
Anna Weinberg and E. David Klonsky \\ Stony Brook University
}

\begin{abstract}
The construct of emotion dysregulation increasingly has been used to explain diverse psychopathologies across the lifespan. The Difficulties in Emotion Regulation Scale (DERS; K. L. Gratz \& L. Roemer, 2004) represents the most comprehensive measure of the construct to date and exhibits good reliability and validity in adults; however, the measure has yet to be tested in adolescents. The present study examined the psychometric properties of the DERS in a community sample of 428 adolescents (ages 13-17 years). Exploratory factor analysis supported a 6-factor structure consistent with the 6 DERS subscales. Internal consistencies for the subscales were good to excellent (alphas ranged from .76 to .89). In support of the measure's construct validity, the DERS exhibited robust correlations with psychological problems reflecting emotion dysregulation, specifically depression, anxiety, suicidal ideation, eating disorders, alcohol use, and drug use. Intercorrelations among the DERS subscales ranged from negligible to high (range: $r=.04$ to $r=.68$ ), and potential problems with discriminant validity were noted. In general, results support the reliability and validity of the DERS as a measure of emotion dysregulation in adolescents.
\end{abstract}

Keywords: emotion regulation, adolescents, Difficulties in Emotion Regulation Scale

The construct of emotion dysregulation has been used to explain diverse psychopathologies. Elaborated emotion-dysregulation theories have been applied to depression (Gross \& Muñoz, 1995), generalized anxiety disorder (Mennin, Heimberg, Turk, \& Fresco, 2005), alcohol/substance abuse (Fox, Axelrod, Paliwal, Sleeper, \& Sinha, 2007; Fox, Hong, \& Sinha, 2008), self-injury (e.g., Klonsky, 2009), suicide (Zlotnick, Donaldson, Spirito, \& Pearlstein, 1997), eating disorders (e.g., Sim \& Zeman, 2005, 2006), and borderline personality disorder (Linehan, 1993; Glenn \& Klonsky, 2009).

Despite growing consensus regarding the importance of emotion dysregulation in psychopathology, the field has not yet reached an agreement on the construct's definition. Multiple components of emotion regulation have been proposed, including abilities to identify emotions, generate new emotional experiences, selectively deploy attention, reinterpret potentially distressing cognitions, modify potentially distressing situations, and modulate response (e.g., Eisenberg \& Spinrad, 2004; Gross \& Thompson, 2007). It is probable that emotion regulation is a multidimensional process involving numerous components. As Cole, Martin, and Dennis (2004) argued, for the study of emotion regulation to progress, researchers need to explicitly state their working hypothesis of emotion regulation and take a multidimensional approach to measuring it. The present study therefore uses the conceptualization offered by Gratz and Roemer (2004), which incorporates many of

Anna Weinberg and E. David Klonsky, Department of Psychology, Stony Brook University.

We thank Thomas Olino for his comments on earlier versions of this article and for statistical consultation.

Correspondence concerning this article should be addressed to E. David Klonsky, Department of Psychology, Stony Brook University, Stony Brook, NY 11794-2500. E-mail: edklonsky@gmail.com the aforementioned components. Gratz and Roemer (2004) defined emotion regulation as "involving the (a) awareness and understanding of emotions, (b) acceptance of emotions, (c) ability to control impulsive behaviors and behave in accordance with desired goals when experiencing negative emotions, and (d) ability to use situationally appropriate emotion regulation strategies flexibly to modulate emotional responses as desired in order to meet individual goals and situational demands" (p. 42).

Emotion-dysregulation theories are increasingly being applied to child and adolescent disorders, as well as adult psychopathologies. In 2004, Child Development, a leading child and developmental journal, devoted a special issue to the conceptualization and mental health implications of emotion dysregulation (Volume 75, Issue 2, March 2004). In the past 3 years alone, phenomena such as nonsuicidal self-injury in adolescents (e.g., Klonsky, 2009), adolescent depression (e.g., Yap, Allen, \& Sheeber, 2007), externalizing spectrum disorders in children and adolescents (e.g., Mullin \& Hinshaw, 2007), and adolescent bipolar disorder (Dickstein \& Leibenluft, 2006) have been viewed through an emotionregulation lens. Although measures of emotion regulation in children have been developed (e.g., Children's Emotion Management Scales [Zeman, Shipman, \& Penza-Clyve, 2001], Emotion Expression Scale for Children [Penza-Clyve \& Zeman, 2002]), they have not been adapted for use with adolescents (but see Sim \& Zeman, 2006). A recent review of emotional assessments in children and adolescents called for more rigorous assessment of emotion regulation but did not identify any valid measures that capture the construct in adolescents (Zeman, Klimes-Dougan, Cassano, \& Adrian, 2007). Continued progress in research with adolescents is likely to be slowed because the field lacks a comprehensive measure of emotion dysregulation whose psychometric properties have been established in this age group.

Despite these difficulties, the evolution of the construct of emotion dysregulation has laid a foundation for the development 
of measures that are reliable, valid, and grounded in theory. The Difficulties in Emotion Regulation Scale (DERS; Gratz \& Roemer, 2004) may represent the most comprehensive measure to date, assessing six clinically relevant domains of emotion dysregulation: nonacceptance of emotion responses (Nonacceptance), lack of emotional awareness (Awareness), limited access to emotionregulation strategies (Strategies), difficulties engaging in goaldirected behavior when emotionally aroused (Goals), impulsecontrol difficulties (Impulse), and lack of emotional clarity (Clarity).

The psychometric properties of the DERS have been established in a variety of adult populations. In young adults from a college sample, the full measure and its subscales were found to have good internal consistency, test-retest reliability, and construct validity (Gratz \& Roemer, 2004; Tull \& Roemer, 2007). The DERS has also exhibited good construct validity in adult psychiatric patients. Specifically, the measure has demonstrated sensitivity to change due to successful clinical intervention (Gratz \& Gunderson, 2006; Gratz, Lacroce, \& Gunderson, 2006) and correspondence with a behavioral measure of emotion dysregulation (Gratz, Rosenthal, Tull, Lejuez, \& Gunderson, 2006). The DERS has therefore gained wide acceptance as a reliable and valid measure of emotion dysregulation in adults and has been used in studies of adults with post-traumatic stress symptoms (Tull, Barrett, McMillan, \& Roemer, 2007), alcoholism (Fox et al. 2008), substance disorders (Gratz, Bornovalova, Delany-Brumsey, Nick, \& Lejuez, 2007), eating disorders (Whiteside et al., 2006), and generalized anxiety disorder (McLaughlin, Mennin, \& Farach, 2007).

However, the psychometric properties of the DERS have not been established in other age groups. The present study was designed to help meet this need. Specifically, this study examined the psychometric properties of the DERS in a large community sample of adolescents (ages 13-17 years). We used exploratory factor analysis (EFA) to examine the measure's structure, and we examined the construct validity of the DERS via correlations with six variables theoretically related to emotion dysregulation: depression, anxiety, suicidal ideation, eating disorders, alcohol use, and drug use.

\section{Method}

Seven hundred students at a high school in Queens County, New York were recruited to participate. Four hundred twenty-eight who returned signed parental permission forms and provided assent composed the study sample and were administered the study protocol. Sixty-one percent $(n=261)$ of these were female. In the target sample, age ranged from 13 to 17 years, and the ethnic distribution was 53\% Caucasian, 19\% Hispanic, 15\% Asian, 11\% African American, and 3\% mixed racial heritage.

We used the DERS (Gratz \& Roemer, 2004), a 36-item, sixscale self-report measure designed to assess clinically relevant difficulties in emotion regulation, to evaluate emotion dysregulation. Six items compose the Nonacceptance subscale (e.g., "When I'm upset, I become angry with myself for feeling that way"), five compose the Goals subscale (e.g., "When I'm upset, I have difficulty focusing on other things"), six compose the Impulse subscale (e.g., "When I'm upset, I become out of control"), six compose the Awareness subscale (e.g., "I pay attention to how I feel"), eight compose the Strategies subscale (e.g., "When I'm upset, I know that I can find a way to eventually feel better"), and five compose the Clarity subscale (e.g., "I have difficulty making sense out of my feelings"). Participants indicate on a Likert scale how often each item applies to themselves, with responses ranging from 1 (almost never) to 5 (almost always). Higher scores indicate greater difficulty with emotion regulation.

We used the Patient Health Questionnaire-Adolescent (PHQ-A; Johnson, Harris, Spitzer, \& Williams, 2002), an 83-item self-report measure, to assess the presence of depressive symptoms, anxiety symptoms, suicidal ideation, eating disorder symptoms, and alcohol and substance abuse. The PHQ-A shows good agreement with diagnoses made by structured interview, as well as strong agreement with indices of impaired functioning and distress and satisfactory sensitivity and specificity (Johnson et al., 2002). In the present study, we used the PHQ-A to establish continuous measures of symptom severity, rather than binary diagnoses, as our primary interest was in establishing the utility of the DERS in a community, rather than clinical, adolescent sample.

\section{Results}

To examine the structure of the DERS, we initially conducted an EFA (principle axis factoring in the Statistical Package for the Social Sciences (SPSS; SPSS Inc., 2005), with promax rotation to allow factors to correlate). Examination of the scree plot and eigenvalues $>1$ yielded empirical justification for retaining either six or seven factors. These results are similar to the original EFA conducted by Gratz and Roemer (2004), in which they found empirical support for six and seven factor solutions and concluded that six was more conceptually interpretable. Similarly, our seventh factor appeared to represent an artifact of item format, rather than content (i.e., the factor consisted of reverse-coded items from four different DERS parent scales). Therefore, we opted for the six-factor solution. To identify item loadings on the six factors, we ran a final EFA (with promax rotation), in which we specified that six factors be extracted. The six factors accounted for $62.7 \%$ of the variance and mapped well onto the six DERS subscales. To aid in the interpretation of the factor solution, we examined whether each item had a loading of .4 or greater on its parent scale, although we used the threshold of .4 as a guide to interpretation, rather than as a rigid cutoff. The original study examining the structure of the DERS (Gratz \& Roemer, 2004) also used a threshold of .4. In the present study, 30 of the 36 DERS items had loadings above .4 on only their parent scale. Of the remaining six items, three (i.e., Items 7, 22, and 30) loaded onto their parent scale as well as another scale, one did not load onto its parent scale but loaded $>.4$ onto another scale (i.e., Item 1 from the Clarity scale loaded $>.4$ onto the Awareness scale), and two did not load $>.4$ onto any scale (i.e., Item 3 from Impulse loaded .34 on both its parent scale and Strategies, and Item 23 from Nonacceptance loaded .37 on Strategies). Loadings for all items on each of the six factors are presented in Table 1 .

Because we found the structure of the DERS in our sample to be highly similar to its structure in previous work, for subsequent analyses, we scored the DERS using all items from the original scales. We calculated Cronbach's alpha to determine the internal consistency for the overall measure and each of the subscales. The DERS was found to have high internal consistency $(\alpha=.93)$. Four of the DERS subscales were found to have excellent internal 


\begin{tabular}{|c|c|c|c|c|c|c|}
\hline \multirow[b]{2}{*}{ Item } & \multicolumn{6}{|c|}{ Factor } \\
\hline & 1 & 2 & 3 & 4 & 5 & 6 \\
\hline \multicolumn{7}{|l|}{ Strategies } \\
\hline 35. Delayed recovery & .80 & -.11 & -.04 & .03 & -.10 & .03 \\
\hline 28. Nothing I can do & .80 & -.04 & .07 & -.08 & .05 & .03 \\
\hline 16. End up depressed & .78 & -.04 & -.04 & -.03 & -.08 & .14 \\
\hline 31. Can only wallow & .63 & .24 & -.08 & -.01 & .03 & -.07 \\
\hline 30. Feel bad about self & .63 & .44 & -.14 & -.03 & .02 & -.07 \\
\hline 15. Remain upset & .62 & -.04 & .20 & .03 & -.11 & .02 \\
\hline 22. Can find a way to feel better (R) & .58 & -.12 & .01 & .03 & .44 & -.13 \\
\hline 36. Emotions overwhelming & .56 & .01 & .11 & .09 & -.10 & .12 \\
\hline \multicolumn{7}{|l|}{ Nonacceptance } \\
\hline 21. Feel ashamed & -.12 & .90 & .05 & .01 & .01 & -.01 \\
\hline 12. Become embarrassed & -.16 & .80 & -.01 & .08 & .07 & .02 \\
\hline 25. Feel guilty & .04 & .77 & .02 & .03 & .04 & -.07 \\
\hline 29. Become irritated & .34 & .59 & .01 & -.03 & .05 & -.06 \\
\hline 11. Become angry & .15 & .49 & .13 & -.08 & .01 & .12 \\
\hline 23. Feel weak & .37 & .20 & -.05 & .10 & -.14 & .16 \\
\hline \multicolumn{7}{|l|}{ Impulse } \\
\hline 14. Become out of control & -.02 & -.03 & .93 & -.04 & .01 & -.01 \\
\hline 32. Lose control & .03 & .03 & .86 & -.01 & .04 & -.04 \\
\hline 27. Difficulty controlling & -.08 & .12 & .82 & .11 & .02 & -.02 \\
\hline 19. Feel out of control & .09 & -.01 & .77 & -.02 & -.01 & .11 \\
\hline 24. Remain in control $(\mathrm{R})$ & .13 & -.17 & .29 & .16 & .37 & -.07 \\
\hline 3. Emotions overwhelming and out of control & .34 & .07 & .34 & .01 & -.06 & .10 \\
\hline \multicolumn{7}{|l|}{ Goals } \\
\hline 18. Difficulty focusing & -.12 & .02 & .03 & .92 & -.14 & .06 \\
\hline 26. Difficulty concentrating & .03 & .04 & -.06 & .88 & -.06 & -.03 \\
\hline 13. Difficulty getting work done & -.04 & .07 & .07 & .81 & -.06 & -.08 \\
\hline 20. Still get things done $(\mathrm{R})$ & .16 & -.13 & -.01 & .53 & .32 & -.18 \\
\hline 33. Difficulty thinking about anything else & .29 & .01 & .03 & .53 & -.10 & .02 \\
\hline \multicolumn{7}{|l|}{ Awareness } \\
\hline 8. Care about feelings $(\mathrm{R})$ & -.02 & .17 & .02 & -.10 & .70 & .01 \\
\hline 10. Acknowledge emotions (R) & .03 & -.02 & -.03 & -.11 & .66 & -.14 \\
\hline 2. Pay attention (R) & -.18 & .09 & -.06 & .12 & .64 & .24 \\
\hline 6. Attentive to feelings (R) & -.08 & .03 & .06 & -.03 & .55 & .18 \\
\hline 17. Feelings valid and important (R) & -.08 & .03 & -.01 & -.09 & .51 & -.02 \\
\hline 34. Take time to figure out feelings (R) & -.01 & -.02 & .12 & -.06 & .51 & -.13 \\
\hline \multicolumn{7}{|l|}{ Clarity } \\
\hline 9. Confused about feelings & .11 & -.01 & -.02 & -.03 & -.09 & .73 \\
\hline 5. Difficulty making sense & .09 & -.05 & .09 & -.07 & .01 & .71 \\
\hline 4. No idea how feeling & .01 & .04 & .02 & -.09 & .04 & .68 \\
\hline 7. Know how feeling (R) & .05 & -.10 & -.07 & .08 & .41 & .49 \\
\hline 1. Clear about feelings $(R)$ & -.01 & .06 & -.14 & .18 & .40 & .30 \\
\hline
\end{tabular}

Note. $\quad$ DERS $=$ Difficulties in Emotion Regulation Scale (Gratz \& Roemer, 2004). $\mathrm{R}$ denotes that the item is reverse coded. Loadings onto parent scale are in bold. Loadings $>.30$ onto another scale are in italics.

consistency $(\alpha>.80)$, and the Awareness and Clarity subscales exhibited adequate internal consistency $(\alpha \mathrm{s}=.77$ and .76 , respectively). Table 2 displays internal consistencies, means, and standard deviations for each subscale, as well as the correlations among the six DERS subscales. Correlations among the subscales ranged from negligible to high $(.04 \leq r \leq .68)$.

We next examined gender differences on the total DERS scale and the six subscales. There was no significant difference between boys $\left(M=76.6, s_{M}=1.8\right)$, and girls $\left(M=80.2, s_{M}=1.5\right)$ on the overall DERS, $F(1,307)=3.19, p=.08$. However, girls scored higher than boys on Goals, Strategies, and Clarity subscales (see Table 2 for details).

To study construct validity, we examined the relationship of the DERS to symptoms of six psychological problems that have been conceptualized in terms of emotion-regulation deficits: depression, suicidal ideation, anxiety, eating disorders, alcohol abuse, and drug abuse. As expected, the DERS exhibited significant correlations with all six. It is notable that although Awareness was modestly correlated with symptoms of eating disorders, it was the only scale that did not exhibit significant correlations with any of the other clinical variables of interest, and its correlations with clinical variables were the smallest of all the DERS subscales. Although the correlation with symptoms of eating disorders is statistically significant, it is very small $(r=.13)$ and not reliably different from the nonsignificant correlations with other clinical variables. In general, symptoms of depression exhibited the highest correlations with the subscales of the DERS, and symptoms of alcohol and substance abuse displayed the lowest correlations with subscales 
Table 2

Means (Overall and for Female and Male Participants), Standard Deviations, and Intercorrelations for DERS Subscales (N=428)

\begin{tabular}{|c|c|c|c|c|c|c|c|c|c|c|c|c|c|}
\hline \multirow[b]{2}{*}{ Variable } & \multicolumn{2}{|c|}{ Overall } & \multicolumn{2}{|c|}{ Female } & \multicolumn{2}{|c|}{ Male } & \multirow{2}{*}{$\begin{array}{c}\text { DERS } \\
\text { total }\end{array}$} & \multirow[b]{2}{*}{ Nonacceptance } & \multirow[b]{2}{*}{ Goals } & \multirow[b]{2}{*}{ Impulse } & \multirow[b]{2}{*}{ Awareness } & \multirow[b]{2}{*}{ Strategies } & \multirow[b]{2}{*}{ Clarity } \\
\hline & $M$ & $S D$ & $M$ & $S D$ & $M$ & $S D$ & & & & & & & \\
\hline DERS total & 78.9 & 23.2 & 80.2 & 23.4 & 76.6 & 22.6 & $(.93)$ & & & & & & \\
\hline Nonacceptance & 11.3 & 5.3 & 11.3 & 4.9 & 11.0 & 6.0 & .73 & $(.86)$ & & & & & \\
\hline Goals & 13.8 & 5.3 & $14.2^{*}$ & 5.5 & 13.0 & 4.8 & .74 & .44 & $(.87)$ & & & & \\
\hline Impulse & 11.9 & 5.6 & 11.8 & 5.6 & 11.8 & 5.7 & .80 & .48 & .58 & $(.88)$ & & & \\
\hline Awareness & 15.5 & 4.9 & 14.9 & 4.8 & 16.1 & 5.0 & .37 & .04 & .06 & .16 & $(.77)$ & & \\
\hline Strategies & 15.6 & 7.0 & $16.3^{*}$ & 7.4 & 14.4 & 6.5 & .87 & .65 & .61 & .68 & .07 & $(.89)$ & \\
\hline Clarity & 11.1 & 4.3 & $11.6^{*}$ & 4.5 & 10.3 & 3.8 & .68 & .41 & .35 & .39 & .38 & .48 & $(.76)$ \\
\hline
\end{tabular}

Note. $\quad$ DERS $=$ Difficulties in Emotion Regulation Scale (Gratz \& Roemer, 2004). Correlations above .10 are statistically significant at an alpha level of .01. Internal consistency for each scale, as indicated by coefficient alpha, is presented in parentheses.

${ }^{*} p<.01$ between means for male and female participants.

of the DERS. Correlations between the six clinical variables and each DERS subscale are presented in Table 3.

\section{Discussion}

Although the concept of emotion dysregulation has been used to explain diverse clinical problems, the field lacks a reliable and valid measure of emotion dysregulation for use in adolescents. The purpose of this study was to report the psychometric properties of the DERS (a multidimensional measure of emotion regulation difficulties) in a large community sample of adolescents. In general, results support the factor structure, reliability, and validity of the DERS in adolescents, suggesting the DERS is a useful tool for evaluating theories of emotion regulation and dysregulation in adolescents.

Although the present study largely supported the psychometric properties of the DERS, two concerns deserve comment. First, one of the six subscales appeared potentially problematic. The Awareness subscale exhibited modest, rather than strong, internal consistency and, more important, was the only subscale not to correlate with five of the six clinical variables theoretically associated with emotion dysregulation. Moreover, the Awareness subscale

Table 3

Descriptive Statistics for DERS Scales and Their Correlations With Dimensional Scores of Depression, Anxiety, Suicidal Ideation, Eating Disorders, Alcohol Use, and Drug Use $(N=428)$

\begin{tabular}{lcccccc}
\hline \multicolumn{1}{c}{ Variable } & Depression & Anxiety & $\begin{array}{c}\text { Suicidal } \\
\text { ideation }\end{array}$ & $\begin{array}{c}\text { Eating } \\
\text { disorders }\end{array}$ & $\begin{array}{c}\text { Alcohol } \\
\text { use }\end{array}$ & $\begin{array}{c}\text { Drug } \\
\text { use }\end{array}$ \\
\hline DERS total & .65 & .42 & .43 & .38 & .24 & .19 \\
Nonacceptance & .49 & .31 & .32 & .29 & .17 & .11 \\
Goals & .51 & .30 & .22 & .24 & .18 & .12 \\
Impulse & .52 & .38 & .37 & .30 & .22 & .19 \\
Awareness & .09 & .02 & .09 & .13 & .04 & .03 \\
Strategies & .65 & .43 & .50 & .34 & .25 & .20 \\
Clarity & .43 & .30 & .26 & .28 & .11 & .11 \\
\hline
\end{tabular}

Note. DERS $=$ Difficulties in Emotion Regulation Scale (Gratz \& Roemer, 2004). Correlations above .19 are statistically significant at an alpha level of .001. Correlations above .1 are significant at an alpha level of .05 . exhibited a substantially lower correlation with the total DERS scale, compared with other subscales, suggesting that it may be less closely associated with the parent construct of emotion regulation. Because at least one other study reported problematic psychometric properties for Awareness (Tull \& Roemer, 2007), future research should further explore the utility and validity of this subscale. It may be that the language of the items in the awareness subscale, (e.g., "When I'm upset, I take time to figure out what I'm really feeling," and "When I'm upset, I believe that my feelings are valid and important") is less appropriate developmentally to adolescents than language in other scales measuring similar constructs. In a study of emotional awareness in adolescents, the "lack of emotional awareness" scale of the Emotion Expression Scale for Children (Penza-Clyve \& Zeman, 2002) exhibited good internal consistency $(\alpha=.81)$ in girls ages 11 to 15 (Sim \& Zeman, 2005). The items on that scale appear to have more simple and age-appropriate wording and include phrasing such as, "I have feelings that I can't figure out."

Another potential problem regards the discriminant validity of DERS subscales. Previous research suggests that different types of emotion-regulation deficits are present in externalizing, compared with internalizing, spectrum disorders (for a review, see Zeman, Cassano, Perry-Parrish, \& Stegall, 2006); however, further evidence in support of this is needed. In the present study, the DERS subscales showed similar patterns of correlations for both the internalizing (i.e., depression, anxiety, suicidal ideation) and externalizing disorders (i.e., alcohol and drug use). To the extent that emotion-regulation difficulties should differ between internalizing and externalizing disorders, then, this casts some doubt on the discriminant utility of the DERS subscales. However, there remains the possibility that, in fact, similar emotion-regulation deficits are seen in a variety of different disorders. In addition, intercorrelations among some of the subscales were high (up to $r=.68$ ), which could limit discriminant validity. Future work should continue to evaluate the discriminant validity of DERS subscales.

Evidence of gender differences in emotion dysregulation were also of interest. Although there were no differences between male and female participants on the overall DERS, girls had slightly higher scores than boys on three subscales (Goals, Strategies, and Clarity). That female participants might report greater difficulty in 
pursuing goals and formulating strategies in the presence of powerful emotions may be related to the fact that women report experiencing greater emotional intensity than do men (Gross \& John, 1998). However, there is also evidence contradictory to our findings that women in fact report greater emotional clarity than do men (Barrett, Lane, Sechrest, \& Schwartz, 2000) and that women use more emotion-regulation strategies than do men (Stanton, Kirk, Cameron, \& Danoff-Burg, 2000). These studies were primarily conducted in adult samples, however. In children, there is evidence that male and female children use different emotionregulation strategies; whereas girls endorse the substitution of one emotional expression for another (e.g., sadness for anger), boys endorse preferences for neutralizing their emotional expressions (Zeman et al., 2006). Given the multiple, complex forcesdevelopmental, socio-cultural, and biological-that determine emotional responding within and between genders (e.g., Wager \& Ochsner, 2005), such discrepancies further illustrate the need for careful work examining emotion-regulation processes in adolescent samples.

This study has several limitations. First, the clinical variables used to examine construct validity were assessed via self-report questionnaire. Typically, semistructured interviews are considered more reliable and valid diagnostic measures than are self-report instruments. Although the diagnostic questionnaire used in the present study was validated against semistructured interviews, its use may have introduced additional measurement error, which in turn may have reduced the magnitude of the correlations with the DERS. In addition, future research should examine other measures of emotion regulation as criterion variables against which to evaluate convergent validity of the DERS. Unfortunately, there is a dearth of such measures developed for adolescents, but some measures developed for children and pre-adolescents may be appropriate for adolescents (e.g., Sim \& Zeman, 2006; Zeman et al., 2001).

Third, although the sample was large and diverse, it was drawn from a single high school and therefore cannot be assumed to be representative of the larger population of adolescents in the United States. Properties of the DERS may vary by demographic context. For example, research suggests that emotion generative and regulatory processes may differ according to SES and cultural milieu (e.g., Raver, 2004). In addition, given the multiple developmental changes that occur in the transition from early to late adolescence (physiological, neurological, social, etc.), the structure and validity of the DERS may be different or suboptimal for younger adolescents. A comparison of the factor structure and validity across demographically diverse samples is an important direction for future study.

\section{References}

Barrett, L., Lane, R., Sechrest, L., \& Schwartz, G. (2000). Sex differences in emotional awareness. Personality and Social Psychology Bulletin, 26(9), 1027.

Cole, P. M., Martin, S. E., \& Dennis, T. A. (2004). Emotion regulation as a scientific construct: Methodological challenges and directions for child development research. Child Development, 75, 317-333.

Dickstein, D. P., \& Leibenluft, E. (2006). Emotion regulation in children and adolescents: Boundaries between normalcy and bipolar disorder. Development and Psychopathology, 18, 1105-1131.
Eisenberg, N., \& Spinrad, T. L. (2004). Emotion-related regulation: Sharpening the definition. Child Development, 75, 334-339.

Fox, H., Axelrod, S., Paliwal, P., Sleeper, J., \& Sinha, R. (2007). Difficulties in emotion regulation and impulse control during cocaine abstinence. Drug and Alcohol Dependence, 89, 298-301.

Fox, H. C., Hong, K. A., \& Sinha, R. (2008). Difficulties in emotion regulation and impulse control in recently abstinent alcoholics compared with social drinkers. Addictive Behaviors, 33, 388-394.

Glenn, C., \& Klonsky, E. D. (2009). Emotion dysregulation as a core feature of borderline personality disorder. Journal of Personality Disorders, $23,20-28$.

Gratz, K. L., Bornovalova, M. A., Delany-Brumsey, A., Nick, B., \& Lejuez, C. W. (2007). A laboratory-based study of the relationship between childhood abuse and experiential avoidance among inner-city substance users: The role of emotional non-acceptance. Behavior Therapy, 38, 256-268.

Gratz, K. L., \& Gunderson, J. G. (2006). Preliminary data on an acceptance-based emotion regulation group intervention for deliberate self-harm among women with borderline personality disorder. Behavior Therapy, 37, 25-35.

Gratz, K. L., Lacroce, D., \& Gunderson, J. G. (2006). Measuring changes in symptoms relevant to borderline personality disorder following shortterm treatment across partial hospital and intensive outpatient levels of care. Journal of Psychiatric Practice, 12, 153-159.

Gratz, K. L., \& Roemer, L. (2004). Multidimensional assessment of emotion regulation and dysregulation: Development, factor structure, and initial validation of the Difficulties in Emotion Regulation Scale. Journal of Psychopathology and Behavioral Assessment, 26, 41-54.

Gratz, K. L., Rosenthal, M. Z., Tull, M. T., Lejuez, C. W., \& Gunderson, J. G. (2006). An experimental investigation of emotion dysregulation in borderline personality disorder. Journal of Abnormal Psychology, 115, $850-855$.

Gross, J., \& John, O. (1998). Mapping the domain of expressivity: Multimethod evidence for a hierarchical model. Journal of Personality and Social Psychology, 74, 170-191.

Gross, J. J., \& Muñoz, R. F. (1995). Emotion regulation and mental health. Clinical Psychology: Science \& Practice, 2, 151-164.

Gross, J. J., \& Thompson, R. A. (2007). Emotion regulation: Conceptual foundations. In J. J. Gross (Ed.), Handbook of emotion regulation (pp. 581-605). New York: Guilford Press.

Johnson, J. G., Harris, E. S., Spitzer, R. L., \& Williams, J. B. (2002). The Patient Health Questionnaire for Adolescents: Validation of an instrument for the assessment of mental disorders among adolescent primary care patients. Journal of Adolescent Health, 30, 196-204.

Klonsky, E. D. (2009). The functions of self-injury in young adults who cut themselves: Clarifying the evidence for affect-regulation. Psychiatry Research, 166, 260-268.

Linehan, M. M. (1993). Cognitive-behavioral treatment of borderline personality disorder. New York: Guilford Press.

McLaughlin, K. A., Mennin, D. S., \& Farach, F. J. (2007). The contributory role of worry in emotion generation and dysregulation in generalized anxiety disorders. Behaviour Research and Therapy, 45, 17351752.

Mennin, D. S., Heimberg, R., Turk, C., \& Fresco, D. M. (2005). Preliminary evidence of an emotion dysregulation model of generalized anxiety disorder. Behaviour Research and Therapy, 43, 1281-1310.

Mullin, B. C., \& Hinshaw, S. P. (2007). Emotion regulation and externalizing disorders in children and adolescents. In Gross, J. J. (Ed.), Handbook of emotion regulation (pp. 523-541). New York: Guilford Press.

Penza-Clyve, S., \& Zeman, J. (2002). Initial validation of the Emotion Expression Scale for Children. Journal of Clinical Child and Adolescent Psychology, 31, 450-457.

Raver, C. C. (2004). Placing emotional self-regulation in sociocultural and socioeconomic contexts. Child Development, 75, 346-353. 
Sim, L., \& Zeman, J. (2005). Emotion regulation factors as mediators between body dissatisfaction and bulimic symptoms in early adolescent girls. Journal of Early Adolescence, 25, 478-496.

Sim, L., \& Zeman, J. (2006). The contribution of emotion regulation to body dissatisfaction and disordered eating in early adolescent girls. Journal of Youth and Adolescence, 35, 207-216.

SPSS Inc. (2005). SPSS 13.0 for Windows [Computer software]. Chicago, IL: SPSS Inc.

Stanton, A., Kirk, S., Cameron, C., \& Danoff-Burg, S. (2000). Coping through emotional approach: Scale construction and validation. Journal of Personality and Social Psychology, 78(6), 1150-1169.

Tull, M. T., Barrett, H. M., McMillan, E. S., \& Roemer, L. (2007). A preliminary investigation of the relationship between emotion-regulation difficulties and posttraumatic stress symptoms. Behavior Therapy, 38, 303-313.

Tull, M. T., \& Roemer, L. (2007). Emotion regulation difficulties associated with the experience of uncued panic attacks: Evidence of experiential avoidance, emotional nonacceptance, and decreased emotional clarity. Behavior Therapy, 38, 378-391.

Wager, T., \& Ochsner, K. (2005). Sex differences in the emotional brain. NeuroReport, 16(2), 85.

Whiteside, U., Chen, E., Neighbors, C., Hunter, D., Lo, T., \& Larimer, M. (2006). Difficulties regulating emotions: Do binge eaters have fewer strategies to modulate and tolerate negative affect? Eating Behaviors, 8, $162-169$.

Yap, M. B. H., Allen, N. B., \& Sheeber, L. (2007). Using an emotionregulation framework to understand the role of temperament and family processes in risk for adolescent depressive disorders. Clinical Child and Family Psychology Review, 10, 180-196.

Zeman, J., Cassano, M., Perry-Parrish, C., \& Stegall, S. (2006). Emotion regulation in children and adolescents. Journal of Developmental and Behavioral Pediatrics, 27, 155-168.

Zeman, J., Klimes-Dougan, B., Cassano, M., \& Adrian, M. (2007). Measurement issues in emotion research with children and adolescents. Clinical Psychology: Science and Practice, 14, 377-401.

Zeman, J., Shipman, K., \& Penza-Clyve, S. (2001). Development and initial validation of the Children's Sadness Management Scale. Journal of Nonverbal Behavior, 25, 187-205.

Zlotnick, C., Donaldson, D., Spirito, A., \& Pearlstein, T. (1997). Affect regulation and suicide attempts in adolescent inpatients. Journal of American Academy of Child Adolescent Psychiatry, 36, 793-798.

Received June 9, 2008

Revision received April 22, 2009

Accepted May 5, 2009

\section{Members of Underrepresented Groups: Reviewers for Journal Manuscripts Wanted}

If you are interested in reviewing manuscripts for APA journals, the APA Publications and Communications Board would like to invite your participation. Manuscript reviewers are vital to the publications process. As a reviewer, you would gain valuable experience in publishing. The $\mathrm{P} \& \mathrm{C}$ Board is particularly interested in encouraging members of underrepresented groups to participate more in this process.

If you are interested in reviewing manuscripts, please write APA Journals at Reviewers@apa.org. Please note the following important points:

- To be selected as a reviewer, you must have published articles in peer-reviewed journals. The experience of publishing provides a reviewer with the basis for preparing a thorough, objective review.

- To be selected, it is critical to be a regular reader of the five to six empirical journals that are most central to the area or journal for which you would like to review. Current knowledge of recently published research provides a reviewer with the knowledge base to evaluate a new submission within the context of existing research.

- To select the appropriate reviewers for each manuscript, the editor needs detailed information. Please include with your letter your vita. In the letter, please identify which APA journal(s) you are interested in, and describe your area of expertise. Be as specific as possible. For example, "social psychology" is not sufficient-you would need to specify "social cognition" or "attitude change" as well.

- Reviewing a manuscript takes time (1-4 hours per manuscript reviewed). If you are selected to review a manuscript, be prepared to invest the necessary time to evaluate the manuscript thoroughly. 